\title{
Privatização e mudanças organizacionais: um estudo de caso sobre transformação cultural e comportamental
}

\section{Privatization and organizational changes: a case study of cultural and behavioral transformation}

\author{
Érica Chulvis do Val Ferreira ${ }^{1}$ \\ Antônio Martinez Fandiño ${ }^{2}$ \\ Lídia Segre ${ }^{3}$ \\ Rejane Prevot Nascimento ${ }^{4}$
}

\begin{abstract}
Resumo
Este artigo tem por objetivo identificar os impactos que mudanças organizacionais oriundas de programa de privatização causam na cultura das empresas e no comportamento dos funcionários. A pesquisa foi realizada em uma empresa do setor de energia privatizada em 1997, com base no método de estudo de caso. A estrutura do estudo de caso consistiu, num primeiro momento, em entrevistas realizadas no nível gerencial, a fim de entender as características e percepções das mudanças empreendidas com a privatização. Posteriormente, foram utilizados questionários fechados para o nível operacional, com o intuito de verificar e estratificar os resultados identificados na primeira etapa. O estudo revelou que as mudanças estratégico-estruturais, culturais e as verificadas nas percepções dos relacionamentos intraorganizacionais foram as que mais impactaram o comportamento dos funcionários. Concluiu-se que as mudanças organizacionais despertaram tanto resistências quanto reações positivas, dependendo da posição hierárquica na organização e da influência de variáveis como: ambiente externo, cultura organizacional, multiculturalismo organizacional, tempo de trabalho na empresa, nacionalidade do empregado e acesso à informação. Este estudo fornece subsídios para uma maior compreensão sobre os impactos dos processos de privatização nas organizações brasileiras, propiciando informações para o gerenciamento de transições corporativas, sejam públicas e/ou privadas.
\end{abstract}

Palavras-chave: mudanças organizacionais; privatizações; cultura organizacional; comportamento organizacional.

\begin{abstract}
This article aims to identify what impacts organizational changes derived from privatization programs cause in the culture of companies and workers' behavior. The research was done in an energy company that was privatized in 1997 and was based on the case study method. The first step in the case study was interviews with managers in order to understand the characteristics and perceptions of the changes that were made following privatization. Closed question questionnaires for the operational level were then applied to verify and stratify the results identified in the first analysis. The study pointed out that the greatest impact on employee behavior had to do with strategic-structural changes, as well as those of a cultural nature and the perceptions of intra-organizational relationships The conclusion drawn from this study is that organizational changes gave rise not only to change-resistant behavior but also to positive reactions depending on hierarchy position in the organization due to the influence of factors such as: external environment, organizational culture, organizational multiculturalism, seniority, nationality and access to information. This work helps to enhance comprehension of the impacts of privatization processes on Brazilian organizations, providing information for the corporate transition management, whether public or private.
\end{abstract}

Key words: organizational changes; privatizations; organizational culture; organizational culture.

Artigo submetido em setembro de 2008 e aceito para publicação em maio 2009.

${ }^{1}$ Mestrado em Administração e Desenvolvimento Empresarial pela Universidade Estácio de Sá. Analista Administrativo da ANAC - Agência Nacional de Aviação Civil. Endereço: Av. Presidente Vargas, 850 - 13ํandar - Centro - Rio de Janeiro - Brasil - CEP: 20.071-001. E-mail: ericachulvis@gmail.com .

2 D.Sc. Engenharia de Produção - Coordenação dos Programas de Pós-Graduação de Engenharia da Universidade Federal do Rio de Janeiro COPPE/UFRJ ; Professor do Mestrado em Gestão e Estratégia em Negócios da Universidade Federal Rural do Rio de Janeiro. Endereço: BR 465, km 7, ICHS - PPGEN - Seropédica/RJ - BRASIL - CEP 23.890.000. E-mail: fandino@ufrrj.br, fandino@gmail.com .

${ }^{3}$ D.Sc. Engenharia de Sistemas e Computação - Coordenação dos Programas de Pós-Graduação de Engenharia da Universidade Federal do Rio de Janeiro - COPPE/UFRJ ; Professora do Mestrado em Administração/UNIGRANRIO. Endereço: Rua da Lapa, 86 / $9^{\circ}$ andar, Centro - Rio de Janeiro/RJ BRASIL - CEP 20021-180. E-mail: micaela@ms.microlink.com.br .

${ }^{4}$ D.Sc. Engenharia de Produção, Coordenação dos Programas de Pós-Graduação de Engenharia da Universidade Federal do Rio de Janeiro COPPE/UFRJ ; Professora do Mestrado em Administração/UNIGRANRIO. Endereço: Rua da Lapa, $86 / 9^{\circ}$ anda r, Centro - Rio de Janeiro/RJ - BRASIL CEP 20021-180. E-mail: rejaneprevot@uol.com.br 


\section{Introdução}

As análises sobre mudança organizacional quase sempre se iniciam com a discussão sobre a velocidade das mudanças sociais, tecnológicas, econômicas e políticas ocorridas no fím do século passado e a respeito de como as organizações precisam adaptar-se a essas mudanças. Reconhecer o impacto dessa velocidade é fundamental para compreender as mudanças de necessidades dos clientes, a redução do ciclo de vida dos produtos e o aumento do número de competidores. Organizações que pretendem competir no mercado atual devem reestruturar-se internamente, o que implica mudar as políticas de recursos humanos, reduzindo o número de níveis hierárquicos e alterando o próprio sentido da hierarquia, dando espaço à figura do líder.

Em virtude do anteriormente exposto, as empresas têm buscado garantir competitividade, tornando seus processos administrativos mais ágeis e reduzindo custos. Nesse sentido, vêm implementando diversas mudanças, como: venda de unidades menos produtivas que não agregam valor ao negócio principal, fusões e aquisições de outras empresas, terceirização de funções e enxugamento da estrutura interna (WETZEL, 2000).

Esse ambiente de mudanças, na virada dos anos 1980 para a última década do século XX, foi marcado pelos movimentos mundiais de abertura de fronteiras comerciais nacionais e, consequentemente, por uma maior internacionalização de mercados. Diante dessa realidade, o Brasil desencadeou um amplo processo de questionamento de antigos paradigmas da economia baseada nos ditames do Estado e protegida de instabilidades (ROSSETTI, 2001).

Entende-se, portanto, que esse cenário tenha representado um dos fatores que levaram à instituição de novas políticas econômicas que atendessem à ordem econômica globalizada. Assim, o governo federal conduziu a privatização de empresas estatais, sem contar o movimento de fusões e de aquisições que igualmente se intensificou no país nos anos 1990 e no início da década seguinte, em decorrência dessa nova orientação estratégica da economia nacional.

As fusões e aquisições também envolveram empresas de países diferentes, suscitando um confronto de culturas distintas. Isso resultou na implementação de formas de gestão marcadas pelo multiculturalismo, que atendessem às especificidades decorrentes dessa junção de culturas num mesmo ambiente organizacional. Em vista disso, Sayão, Tanure e Duarte (2006) apontam para o surgimento de pesquisas abordando as mudanças organizacionais decorrentes desse processo (no qual se incluem as privatizações). Contudo, os autores ressaltam que há lacunas nesses estudos, pois não abordam o impacto dessas transformações na cultura e no comportamento dos indivíduos.

A partir do exposto, este artigo investiga as mudanças organizacionais oriundas da aquisição de uma empresa estatal brasileira por um grupo estrangeiro, analisando os efeitos no comportamento dos funcionários. Nesse sentido, o estudo aqui apresentado partiu da suposição de que essas mudanças organizacionais, quando realizadas sem a participação destes, têm consequências negativas no comportamento dos empregados remanescentes, que podem se converter em obstáculos para sua implantação.

Para isso, a análise partiu do contexto cultural da organização e da perspectiva individual dos funcionários com relação às mudanças organizacionais. A metodologia utilizada baseou-se em pesquisa bibliográfica acerca das temáticas abordadas, em estudo de caso e na pesquisa de campo em uma empresa do setor de gás e energia da cidade do Rio de Janeiro, por meio de entrevistas em profundidade nos níveis gerenciais e na diretoria. Posteriormente, foram aplicados questionários aos funcionários de nível operacional, para melhor compreender as percepções identificadas na pesquisa com os de nível gerencial e com a diretoria.

Este artigo está estruturado em uma parte teórica, na qual são abordados os temas cultura organizacional, multiculturalismo organizacional, estruturas organizacionais, privatizações e mudanças organizacionais. Após uma descrição da metodologia, é apresentado o estudo de caso e a sua análise, além desta introdução e da conclusão. 


\section{Cultura organizacional}

As culturas de uma nação e a cultura de uma organização guardam relação entre si, pois culturas nacionais e subculturas, assim como culturas organizacionais, apresentam pressupostos básicos, artefatos visíveis e outros conjuntos simbólicos (SCHEIN, 1992). Da mesma maneira, cada organização delimita uma cultura organizacional única, gerada e sustentada pelos mais diversos elementos e formas (FREITAS, 1997).

Ao aprofundarmos essa visão, verificamos que a cultura organizacional apresenta dois níveis. No primeiro nível, em que os elementos são visíveis, encontram-se eventos e comportamentos observáveis, como, por exemplo, o modo dos indivíduos se vestirem e agirem, os símbolos, as histórias e cerimônias compartilhadas pelos membros da organização. No segundo nível, relacionado aos elementos invisíveis, estão os valores subjacentes, as premissas, as ideias e os processos de pensamento, componentes centrais da cultura (DAFT, 1999, 2001). Os elementos visíveis (ou artefatos) refletem os elementos ditos invisíveis, revelando os valores inerentes a uma dada organização. De fácil identificação e observação, os elementos visíveis são, contudo, de difícil interpretação, pois podem explicitar valores de grupos culturais distintos, ou mesmo, antagônicos na organização, cuja cultura não representam como um todo, podendo, dessa forma, serem erroneamente generalizados (SCHEIN, 1992).

Os valores que não podem ser vistos e quantificados sugerem uma maior dificuldade de serem interpretados, pois, na maioria das vezes, são implícitos. No momento em que a organização tenta implantar novas estratégias ou programas de reestruturação, que vão de encontro às suas normas e valores, é que se vê a força da cultura. Dessa forma, fica difícil conseguir mudar qualquer elemento da cultura organizacional (WOOD JR., 1995).

Lopez (2007) ou Morgan (1996) entendem que as organizações podem ser vistas como um grupo integrado que acredita no trabalho conjunto ou estarem divididas em grupos que interpretam a realidade de forma diferente, com aspirações distintas quanto ao que a empresa pode ser. Assim, esses padrões de crenças ou significados compartilhados, na sua integridade ou de forma fragmentada, baseados em várias normas e rituais, influenciam a habilidade da organização em lidar com os desafios que enfrenta. De acordo com Aktouf (1993 apud SAYÃO; TANURE; DUARTE, 2006, p.5):

a cultura consiste na união entre os membros da organização, buscando sustentação e alcance dos objetivos organizacionais. Neste sentido, apresenta-se como instrumento adequado de harmonia entre dirigentes e empregados.

Conclui-se, dessa afirmação, que a cultura organizacional pode ser entendida como um elo que deve promover ligação e identificação entre os diferentes membros da organização, a despeito de suas diferenças hierárquicas, funcionais, educacionais e sociais, para a execução dos objetivos organizacionais.

Esses elementos argumentam a favor do surgimento de várias subculturas dentro da mesma empresa, o que tende a comprometer a construção de uma realidade uniforme que permita às pessoas ver e compreender, da mesma forma, eventos, ações, objetos, expressões e situações particulares (LOPEZ, 2007; MORGAN, 1996). Ainda de acordo com o estudo de Sayão, Tanure e Duarte (2006, p.7), a essência de gerenciar os processos de mudança está:

[...] na habilidade de unir pessoas de diferentes subculturas e fazê-las trabalhar juntas. Construir uma organização eficiente é fundamentalmente uma questão de entrosamento das diferentes subculturas através do encorajamento da evolução de metas, linguagem e procedimentos comuns para resolver problemas.

Nessa ordem de ideias, entende-se que a maneira como os indivíduos constroem seus valores e crenças, os quais irão determinar a cultura da organização, influencia as estruturas formais da mesma. Assim, considera-se que a cultura organizacional é constituída por suposições elaboradas pelos membros da organização, que servem de fundamentação para validar suas atitudes e considerá-las como a maneira correta de interpretar a realidade (SCHEIN, 1992). 


\section{Multiculturalismo organizacional}

A mundialização tem causado impactos importantes para a gestão das organizações, particularmente, no caso de fusões ou aquisições de empresas nacionais por empresas estrangeiras, e consequentemente, sobre a cultura organizacional das empresas adquiridas, assim como das adquirentes. Vários estudos ressaltam o fato de que o sucesso de processos de fusão ou de aquisição de empresas depende, em grande medida, da capacidade dos gestores da mudança de integrar as culturas das organizações envolvidas nesse processo. Marks e Mirvis (1998 apud SAYÃO; TANURE; DUARTE, 2006) enfatizam que o tipo de integração cultural escolhido pelos gestores da mudança influencia no grau de incorporação dessa mudança. Pesquisadores apontam que, no mundo gerencial, a influência da cultura nacional sobre a cultura organizacional adquire maior relevância quando são considerados os modelos de gestão pelas multinacionais e que são implementados nas organizações (FREITAS, 1997; HENNART; ZENG, 2002; LYLES; SALK, 1996). Esses modelos e práticas gerenciais elaborados em outros países são permeados de pressupostos e valores culturais que tendem a ser diferentes e/ou conflitantes com os da sociedade receptora.

A fim de obter um modelo de integração cultural que favoreça a implementação bem-sucedida da mudança organizacional, obtendo-se o melhor das características da gestão de cada empresa, os processos de mudança organizacional que permeiam as fusões e aquisições devem ser precedidos de um intenso trabalho de preparação dos indivíduos. Essa preparação visa diminuir a resistência aos novos padrões culturais, assim como minimizar o sofrimento dos funcionários diante da instabilidade e da insegurança causadas por esse tipo de transformação, tal como afirmam Sayão, Tanure e Duarte (2006, p.3): "Não basta adotar a solução de substituir pessoas que não se enquadrem nos novos sistemas e valores". A defesa dos valores, crenças e costumes de uma determinada organização por meio de seus funcionários representa um comportamento de adesão à cultura dessa organização. Assim, uma nova gestão organizacional, ao se interpor a uma cultura já internalizada pelo coletivo, traz em seu bojo modificações estruturais, tecnológicas e culturais, sugerindo um enfrentamento de culturas que pode resultar em um choque cultural (HENNART; ZENG, 2002; SIMON; LANE, 2004).

Algumas pesquisas têm concluído que para evitar os conflitos organizacionais advindos de mudanças culturais é necessário compreender as características próprias de cada país (FREITAS, 1997; ROSSETTI, 2001). Entretanto, não se deve subestimar a preponderância das culturas organizacionais de cada empresa, pois qualquer que seja a cultura nacional, esta se baseia, principalmente, em valores profundamente arraigados na sociedade como um todo (SIMON; LANE, 2004). Já a cultura organizacional se fundamenta, primariamente, em crenças compartilhadas nas práticas e processos organizacionais (HOFSTEDE et al, 1990; POTHUKUCHI et al, 2002).

Dessa forma, os valores que fundamentam a maneira como se percebe e interpreta a realidade diferem de organização para organização, bem como, entre os indivíduos que as compõem, cujo coletivo está formado pelos elementos da estrutura informal da empresa. Portanto, é necessário entender as diferenças individuais e culturais para a implementação de mudanças organizacionais, já que essas ações dependem fundamentalmente das mudanças de atitudes e de percepções dos indivíduos da organização, dentro de uma dada estrutura organizacional.

\section{Estruturas organizacionais}

Segundo Evans e Davis (2005), a dinâmica das relações sociais, econômicas e políticas levam as organizações a adotar estruturas diferentes, relevantes na definição do comportamento e das atitudes dos empregados. Percebe-se que a complexidade do mundo do trabalho aponta para o surgimento de comportamentos e atitudes diversificados, que frustram as tentativas de se padronizar o gerenciamento dessa realidade multifacetada. Assim, para lidar com essa complexidade, argumenta-se a favor da importância de se considerar não só a estrutura formal da organização, mas também as relações informais dela decorrentes. 
A estrutura organizacional formal (SALSBURY, 1967 apud DAFT, 2001) determina as relações formais de subordinação, entre as quais, o número de níveis hierárquicos e a amplitude de comando de gerentes e supervisores. Além disso, identifica o agrupamento de indivíduos e departamentos na organização, além de definir as linhas de comunicação entre departamentos para coordenar e integrar esforços.

Por outro lado, percebe-se que a perspectiva informal das organizações aponta para a importância dos relacionamentos humanos para o comportamento dos indivíduos na organização, o que tende a influenciar a organização formal. Na perspectiva informal da organização, é importante ressaltar a força do poder e da política nas interações humanas e a influência desses dois elementos na organização formal. Esse fato é destacado por Evans e Davis (2005) quando afirmam que a inter-relação decorrente das atividades do cargo se prolonga e se amplia por meio dos momentos no trabalho.

A política, segundo Daft (2001, p.424) "é o uso do poder para conseguir que as coisas sejam feitas". Depreende-se desse conceito, portanto, que a política é uma ferramenta organizacional que pode ser utilizada para realizar coisas positivas e negativas. Em termos de teorias da organização, o referido autor considera que a política é composta por "atividades para adquirir, desenvolver e utilizar poder e outros recursos para obter resultado preferido quando existe incerteza ou desacordo" (Ibid, p.424).

Por outro lado, o poder e a política devem ser usados no processo natural de decisão organizacional para solucionar diferenças entre grupos de interesse na organização (DAFT, 2001; MORGAN, 1996). Nesse sentido, política é o processo de negociação utilizado para superar conflitos e diferenças de opinião, permitindo o manejo da organização de acordo com os objetivos e estratégias traçados por sua direção executiva.

Cabe destacar que as reorganizações alteram responsabilidades e tarefas, o que também afeta a base de poder subjacente a partir das contingências estratégicas. Nessa mesma ordem de ideias, a contratação de novos funcionários, as promoções e as transferências têm grande significado político, pois afetam as relações de confiança e cooperação entre os indivíduos da organização (DAFT, 2001; WALSH, 2004).

Portanto, nos processos de mudanças organizacionais, a incerteza e o desacordo são aspectos que apontam para situações de conflito dentro das organizações. Nas reorganizações estruturais, a política desempenha papel importante, pois essas mudanças atingem as relações de poder e autoridade construídas nas empresas.

\section{Privatização e mudanças organizacionais}

As privatizações conduzem as organizações a mudanças que se iniciam antes mesmo do processo de desestatização se concretizar. Tais mudanças abrangem, em geral, três ações principais, descritas a seguir (BAUMOL; BLINDER; WOLFF, 2003):

i. estratégia de redução da força de trabalho - o objetivo é diminuir custos por meio de aposentadorias, transferências e demissões, incentivadas ou não;

ii. redesenho organizacional - o objetivo é cortar trabalho, em vez de funcionários, eliminando funções, níveis hierárquicos, divisões e produtos; e

iii. estratégia sistêmica - costuma ser observada nos períodos pós-privatização, já que tem característica de longo prazo e visa mudar a organização. Representa um esforço para transformar tanto os valores quanto a cultura da organização.

Os efeitos organizacionais oriundos das mudanças podem ser divididos da seguinte forma: efeitos no ambiente do trabalho, nas relações de trabalho, na eficiência interna e na eficácia organizacional (CALDAS; WOOD, 2007).

Os efeitos no ambiente de trabalho estão relacionados com a deterioração do clima organizacional, com o aumento do nível de conflito e, portanto, de estresse. Pode haver ainda queda na participação em programas de envolvimento de pessoal e perda de familiaridade entre unidades da empresa, advindos de processos de 
mudança. Esses fatos afetam as relações de trabalho - em especial, dos remanescentes -, com ocorrência de: depressão, ansiedade, perda de motivação para trabalhos adicionais, moral abatido e aversão ao risco (BORDIA, 2004). Eles podem desenvolver um profundo sentimento de insegurança em relação à estabilidade do emprego, ressentindo-se de serem obrigados a trabalhar um maior número de horas e de assumir novos trabalhos, realizados anteriormente pelos que saíram, e para os quais não foram preparados.

Os efeitos no que diz respeito à eficiência interna e à eficácia organizacional referem-se à perda de memória organizacional, já que muitos funcionários antigos são desligados nos processos de privatização, assim como à perda coletiva de espírito empreendedor.

Contudo, os remanescentes podem reagir de forma construtiva se entendem que a reestruturação não lhes causa dano algum e se percebem neles próprios capacidade para lidar com a situação. Entretanto, se avaliam o programa de forma negativa, estarão menos propensos a colaborar na implementação das mudanças (WETZEL, 2000).

As abordagens descritas sugerem que o comportamento humano pode ser um fator facilitador ou complicador nos processos de mudanças organizacionais, dependendo de como os funcionários sejam envolvidos no processo: protagonistas (ativos) ou coadjuvantes (passivos). Tal como destacado na seção "Cultura organizacional", deve-se priorizar a preparação dos indivíduos para a mudança, visando reduzir possíveis impactos negativos no seu comportamento.

O objetivo da preparação para a mudança é conscientizar os indivíduos para que estejam aptos a executar suas funções de formas diferentes e a assumir valores novos, abandonando ou transformando seus valores anteriores, em virtude da necessidade de adequação a uma nova realidade (SAYÃO; TANURE; DUARTE, 2006). Muitos dos problemas que ocorrem nos processos de mudança organizacional estão relacionados com a dificuldade de estimular os indivíduos a perceberem uma mesma situação de acordo com um novo sistema de valores, construindo novos padrões de relacionamento e de condução de suas atividades, o que reforça a importância da integração entre a nova cultura e a antiga.

Nesse contexto, a comunicação desempenha relevante papel na condução dos processos de mudança. Ao reduzir o diálogo e o fluxo de informações, mantendo as comunicações restritas e cautelosas, na tentativa de proteger os ideais de mudança, os agentes de mudança contribuem para gerar mais dúvidas e receios. Segundo Motta (2001, p.217) "maior acesso a informações provoca a mente humana, aguça o interesse pela novidade e gera o desejo de fazer diferente e melhor".

A informação tende a facilitar a execução das tarefas, oferecendo mais tranquilidade no trabalho. A participação encoraja os funcionários a discutir, comunicar, fazer sugestões e a ter interesse pela mudança; já a sua ausência leva à submissão ao processo. $\mathrm{O}$ compromisso gera motivação para apoiar a mudança e assegurar que ela funcionará efetivamente (MOTTA, 2001).

As relações de poder também são afetadas pelas mudanças, ao se redistribuir prioridades, recursos e tarefas. Assim, as mudanças têm grande potencialidade de afetarem direitos e prestígios individuais, construídos ao longo da carreira dos empregados. Portanto, quando reduzidos provocam resistências não só daqueles diretamente afetados, como também naqueles que almejam os mesmos benefícios (MOTTA, 2001).

A mudança, vista como um processo político, apresenta aspectos de conflito, pois ressalta diferenças entre percepções individuais e contrapõe pessoas que procuram defender seus interesses (MOTTA, 2001). Portanto, a resistência daí resultante é tanto um fenômeno individual quanto grupal, variando de um indivíduo para outro, devido a fatores pessoais e situacionais. Em decorrência disso, entende-se que, para um indivíduo, a realidade pode ser entendida como uma experiência pessoal. Para cada indivíduo, a realidade é aquilo que ele percebe como real, conforme sua vivência e suas expectativas com relação ao novo (HERNANDEZ; CALDAS, 2002).

Depreende-se do exposto que os atores podem interpretar a mesma realidade de forma diversa, dependendo da maneira como cada um a sentiu e a percebeu. Essas diferenças de sensações e percepções são produtos das 
restrições fisiológicas e psicológicas que caracterizam as próprias diferenças individuais, as quais, em termos de comportamento organizacional, influenciam o desempenho das pessoas no local de trabalho (CALDAS; WOOD, 2007).

Dessa forma, argumenta-se a favor da necessidade de que, nos processos de mudança organizacional, sejam consideradas as características individuais, as quais são impregnadas pela vivência familiar, pelas experiências sociais e pelas percepções de cada um, podendo influenciar o comportamento das pessoas, induzindo-as ao sofrimento.

\section{Mudança organizacional e sofrimento no trabalho}

Não obstante vários autores tenham estudado a temática do sofrimento no trabalho (CHANLAT, 1994, 1996a, 1996b; DEJOURS, 1987, 2000), a questão do sofrimento como consequência das mudanças organizacionais ainda não se coloca como um objeto de estudo recorrente. A percepção da mudança como ameaça gera emoções negativas como frustração, raiva, ansiedade, medo, tristeza, culpa e vergonha (CALDAS; WOOD, 2007; HERNANDEZ; CALDAS, 2002). Esses sentimentos negativos, que geram sofrimento no indivíduo, surgem como resultado de comparações entre a situação real e a situação almejada.

Dejours (1987) entende que o sofrimento no trabalho decorre exatamente da identificação das diferenças entre a situação desejada pelo indivíduo e a situação tal como se apresenta na realidade. Mota et al (2007), numa pesquisa sobre o sofrimento dos empregados decorrente de mudanças organizacionais e referenciando outros estudos, definem o sofrimento no trabalho como uma intensa vivência de sentimentos como medo, insegurança e angústia, em um longo intervalo de tempo, destacando que as empresas necessitam "aprender a mudar sem sofrimento" (Ibid, p.3).

Em seu livro A banalização da injustiça social (2000), Dejours discorre sobre a naturalização do sofrimento dos trabalhadores excluídos nos frequentes processos de mudança das empresas com vistas a obter maior competitividade e agilidade (movimento que ele define como uma estratégia de "guerra"). Esse sofrimento é agravado pela desmobilização política contra a injustiça inerente a esse movimento de descarte dos indivíduos. Nesse contexto, o movimento é entendido como uma resposta necessária das empresas às condições econômicas, configurando-se numa consequência natural do sistema econômico vigente.

As pessoas que dissociam sua percepção do sofrimento alheio do sentimento de indignação causado pelo reconhecimento de uma injustiça adotam, frequentemente, uma postura de resignação. Resignação diante de um "fenômeno": a crise do emprego, considerada uma fatalidade, comparável a uma epidemia, à peste, à cólera e até à aids. Segundo esta concepção, não haveria injustiça, mas apenas um fenômeno sistêmico, econômico, sobre o qual não se poderia exercer nenhuma influência. (DEJOURS, 2000, p.20)

A psicodinâmica do trabalho consistiria em uma área de estudo cujo objeto seria as psicopatologias associadas ao desempenho no trabalho, o que é descrito pelo autor como uma função essencial, pois a própria organização do trabalho torna-se uma fonte de sofrimento para o indivíduo (DEJOURS, 1987). A esse fator são acrescidas, no contexto atual, as consequências da flexibilização da organização e das relações de trabalho:

as infrações às leis trabalhistas, possibilitando demissões injustificadas e sem pagamento de direitos do trabalhador;

exigência de horários de trabalho que extrapolam os limites legais, sob pena de ameaça de demissão ou exclusão;

dispensa sem aviso prévio; e

a adoção de práticas de gestão manipuladoras e ofensivas aos indivíduos, os quais se submetem por receio de perder o emprego. 
O crescente sentimento de infelicidade que permeia as relações de trabalho na atualidade afeta trabalhadores de todos os níveis da estrutura organizacional, não apenas aqueles voltados para a execução de tarefas operacionais, desprovidos de qualificações que lhes permitam maior mobilidade de emprego. Berardi (2005) aponta para o surgimento de uma nova classe de trabalhadores, os trabalhadores do conhecimento, os quais o autor denomina "cognitariado" (ou o novo proletariado). Essa classe estaria submetida a condições de trabalho semelhantes às dos operários do passado, em consequência da crise da nova economia, o que envolve o mesmo tipo de sofrimento decorrente da ansiedade, da instabilidade e da insatisfação com a situação real de trabalho.

Tal noção é reforçada pelas conclusões do já mencionado estudo de Mota et al (2007), realizado com funcionários de diferentes níveis de uma mesma empresa. Os autores verificaram que as mudanças organizacionais provocaram "sentimentos de insatisfação, sofrimento, frustração, estresse e insegurança na vida profissional e, em especial, na vida pessoal" (MOTA et al, 2007, p.12). Apesar de sofrerem com a mudança, os funcionários acreditavam que tal processo era necessário para a sobrevivência da empresa. Por se sentirem inseguros quanto ao seu emprego, afirmavam que esse sofrimento se dava na esfera pessoal e não na profissional, conforme constatado pelos autores: "restando-lhes as relações e atividades pessoais como catalisadores para o descarregamento de sentimentos negativos e recarregamento de forças para enfrentar as turbulências do ambiente empresarial" (Ibid, p.13).

A partir das discussões apresentadas, depreende-se que mudanças organizacionais influenciam o comportamento dos funcionários, seja no âmbito individual - especialmente, por envolver percepções, sentimentos e valores das pessoas - como no âmbito organizacional formal - no que diz respeito a transformações culturais, estruturais, estratégicas e humanas.

\section{Metodologia}

A pesquisa utilizou o método qualitativo de investigação, pois concentrou o estudo na análise do comportamento dos funcionários da PrestA diante das mudanças organizacionais decorrentes da privatização. Quanto aos meios de investigação, foram utilizadas pesquisa bibliográfica, de campo, documental e estudo de caso. Para a análise do estudo de caso foi utilizada a lógica de adequação ao padrão (YIN, 2002), que compara um padrão fundamentalmente empírico com outro de base prognóstica.

O universo da pesquisa de campo considerou 133 funcionários, dos quais, seis diretores, 25 gerentes, 43 chefes de serviço e 59 funcionários administrativos. Foi definida uma amostra de 36 funcionários por tipicidade, pois foram escolhidos indivíduos considerados representativos do universo estudado. Foram escolhidos sujeitos que já faziam parte do quadro funcional da empresa antes da privatização e que permaneceram nela após a mudança de gestão. Também compuseram a pesquisa funcionários que ingressaram na empresa entre julho e dezembro de 1997, após o leilão de privatização. Foi nesse período em que ocorreu um número maior de demissões.

Para fins desta pesquisa, os dados foram coletados por meio de análise de documentos e de pesquisa de campo, utilizando como instrumentos de coleta de dados entrevistas não-estruturadas e semiestruturadas e questionários.

As entrevistas, que permitiram uma análise em profundidade, foram realizadas com os funcionários de nível administrativo, em razão desse nível hierárquico ter sofrido os maiores impactos das mudanças estruturais: enxugamento, mudança de funções e remanejamento. Os questionários foram aplicados no nível hierárquico operacional e elaborados com algumas perguntas fechadas e outras abertas.

A grande massa de dados colhidos na pesquisa de campo foi separada em unidades menores e, em seguida, reagrupada em categorias que se relacionam entre si, de forma a ressaltar os padrões identificados nos discursos dos sujeitos da pesquisa (BRADLEY, 1993). 
A fim de analisar os resultados da pesquisa, à luz dos objetivos geral e específicos propostos neste estudo, os dados coletados nas entrevistas em profundidade e nos questionários foram divididos em quatro etapas.

Na primeira etapa, os dados foram agrupados em três categorias: a) antiguidade; b) nacionalidade e, c) cargo.

$\mathrm{Na}$ segunda etapa, as categorias foram divididas em subcategorias. Assim, a categoria antiguidade foi desmembrada em duas subcategorias, "novos" e "antigos"; a categoria nacionalidade, nas subcategorias "brasileiros" e "espanhóis" e a categoria nível hierárquico, nas subcategorias1 "gerencial" e "administrativo".

Na terceira etapa, cada uma das mudanças ocorridas na PrestA foi analisada de acordo com a percepção dos funcionários de cada uma das subcategorias mencionadas, correlacionando-as com a discussão teórica acerca de mudanças culturais, estratégicas, estruturais e de pessoal.

Na quarta e última etapa, buscou-se identificar padrões de comportamento dos indivíduos diante das mudanças, a partir das informações obtidas dentro de cada subcategoria. Finalmente, os padrões de comportamento dos funcionários ante as mudanças foram relacionados com os padrões de comportamento que indicam atitudes dos indivíduos em relação a mudanças organizacionais, definidos por Caldas e Wood (2007), Motta (2001) e por Hernandez e Caldas (2002), interpretados à luz dessa literatura.

O quadro 1 sintetiza a metodologia utilizada para a análise e interpretação dos dados.

Quadro 1 - Plano de categorias, subcategorias, mudanças e comportamentos organizacionais para análise de dados

\begin{tabular}{|c|c|c|c|c|c|c|}
\hline $\begin{array}{l}1^{\text {a }} \text { Etapa: } \\
\text { Agrupamento } \\
\text { dos sujeitos em } \\
\text { categorias }\end{array}$ & Categorias & & & $\begin{array}{r}\text { Nacionalidad } \\
\text { Nível Hierárqui } \\
\text { Antiguidade }\end{array}$ & & \\
\hline $\begin{array}{l}2^{\mathrm{a}} \text { Etapa: } \\
\text { Distribuição das } \\
\text { categorias em } \\
\text { subcategorias }\end{array}$ & Subcategorias & $\begin{array}{c}1 \\
\text { Brasileiro } \\
\text { Gerencial } \\
\text { Antigo }\end{array}$ & $\begin{array}{c}2 \\
\text { Brasileiro } \\
\text { Gerencial } \\
\text { Novo }\end{array}$ & $\begin{array}{c}3 \\
\text { Brasileiro } \\
\text { Administrativo } \\
\text { Antigo }\end{array}$ & $\begin{array}{c}4 \\
\text { Brasileiro } \\
\text { Administrativo } \\
\text { Novo }\end{array}$ & $\begin{array}{c}5 \\
\text { Espanhol } \\
\text { Gerencial } \\
\text { Novo }\end{array}$ \\
\hline $\begin{array}{l}3^{\text {a Etapa: }} \\
\text { Análise dos } \\
\text { discursos das } \\
\text { subcategorias } \\
\text { sobre as } \\
\text { mudanças }\end{array}$ & $\begin{array}{l}\text { Mudanças } \\
\text { Organizacionais }\end{array}$ & \multicolumn{5}{|c|}{$\begin{array}{l}\text { Mudanças Culturais } \\
\text { Mudanças Estruturais } \\
\text { Mudanças Estratégicas }\end{array}$} \\
\hline $\begin{array}{l}4^{\text {a }} \text { Etapa: } \\
\text { Identificação dos } \\
\text { padrões de } \\
\text { comportamento } \\
\text { encontrados nos } \\
\text { discursos e } \\
\text { relacionamento } \\
\text { com aqueles } \\
\text { definidos na } \\
\text { literatura }\end{array}$ & $\begin{array}{l}\text { Comportamento } \\
\text { ante as } \\
\text { mudanças, } \\
\text { baseado em: }\end{array}$ & \multicolumn{5}{|c|}{$\begin{array}{c}\text { Discussão teórica sobre cultura, estrutura, mudanças e comportamentos } \\
\text { organizacionais }\end{array}$} \\
\hline
\end{tabular}

Fonte: elaborado pelos autores.

Alguns fatores foram limitadores da pesquisa, tais como:

as restrições de acesso ao acervo da empresa; 
a impossibilidade de entrevistar os funcionários afastados após a privatização por terem aderido ao programa de demissão voluntária, por terem se aposentado ou sido demitidos; e

a escolha do método de estudo de caso, já que ele fornece "pouca base para se fazer uma generalização científica" (YIN, 2002, p.29).

Esse mesmo autor, entretanto, explica que os estudos de caso pretendem oferecer generalizações a proposições teóricas e não a populações ou universos. Assim, cabe ao pesquisador adequar essas generalizações a um conjunto de situações particulares.

\section{Estudo de caso}

A empresa em estudo iniciou suas atividades em 1851, a partir da assinatura do contrato de concessão de atividades de produção e distribuição de gás na cidade do Rio de Janeiro. No decorre de sua história, a PrestA esteve sob controle e gestão de proprietários estrangeiros e nacionais: ingleses (1865-1875 e 1910-1967), belgas (1870-1909), brasileiros, (1967-1997, como estatal) e espanhóis (a partir de 1997), sempre mantendo o foco do negócio na distribuição e comercialização de gás.

Apesar de relevante na formação da cultura da empresa, a experiência dos períodos de gestão estrangeira anteriores ao atual acabou sobreposta pela do período estatal, por este ter durado quase um ciclo de atividade trabalhista vigente no país (35 anos). Isso imprimiu à empresa características de estatal brasileira, particularmente, pela estabilidade funcional e pela gestão a partir dos interesses políticos do governante que esteja no poder.

Em setembro de 1995, foi iniciado o processo de mudança para a privatização, mediante uma estratégia de conscientização dos funcionários. Para isso, foram realizadas palestras e a elaborados avisos e notas explicando o contexto político brasileiro da época, a prioridade então dispensada à saída do Estado das atividades produtivas e suas consequências para a empresa. Esse trabalho de conscientização foi direcionado com maior ênfase para os níveis gerenciais, com o fornecimento de informações detalhadas e a viabilização de uma comunicação frequente com os gestores da mudança, o que possibilitou uma compreensão mais clara sobre as transformações a serem empreendidas. Os funcionários dos níveis operacionais e administrativas, contudo, receberam informações esparsas, de modo coletivo, através de palestras e notas internas.

Essa transformação focou principalmente a estrutura, as rotinas organizacionais e os modelos culturais pertinentes ao status quo de estatal, apesar da empresa ser competidora no mercado energético. O processo de reestruturação, que visava compactar os níveis organizacionais - com as consequentes incorporações de funções, fusões de cargos e extinção de setores -, fomentou o enxugamento do corpo funcional, através de plano de incentivo à aposentadoria, de demissões e de aposentadorias não incentivadas, num total aproximado de $63 \%$ dos 3.000 funcionários anteriormente existentes, conforme detalhado no gráfico 1. Tal processo, no entanto, levou à terceirização de serviços; principalmente, aqueles relacionados com as áreas econômicofinanceira, de recursos humanos, de serviços gerais, técnica e comercial. 


\section{Gráfico 1 - Enxugamento das áreas entre dezembro de 1996 e agosto de 1997}

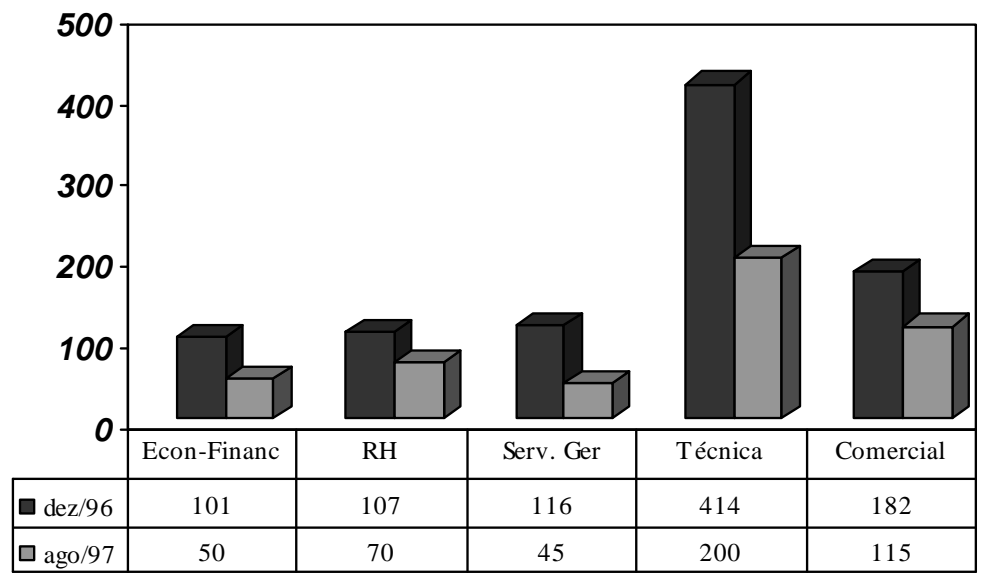

Fonte: elaborado pelos autores.

Os levantamentos desta etapa apontam que não houve um estudo detalhado e aprofundado da estrutura da empresa a fim de avaliar com acuidade que cargos poderiam ser extintos, devido à pressão do governo estadual pela privatização. O critério para as demissões se baseou, então, numa avaliação unilateral do presidente da PrestA, que escolheu quais funcionários deveriam permanecer na nova estrutura organizacional.

Segundo informações coletadas em nível gerencial, o perfil da empresa se caracterizava por uma grande maioria de funcionários admitidos por concurso público, os quais não se sentiam ameaçados em suas funções. Havia uma rígida divisão do trabalho e uma especialização de tarefas, enquanto chefias e setores se preocupavam apenas com os resultados que dissessem respeito estritamente ao seus respectivos departamentos. Essa situação era vista pelos funcionários como algo que não deveria ser alterado. Consequentemente, não havia estímulo para a busca do desenvolvimento profissional.

De acordo com o gerente de uma área que participou ativamente da mudança, a cultura organizacional da empresa, antes da privatização, era caracterizada por comportamentos individuais de acomodação, numa situação de pouca ou quase nenhuma competitividade interna. A condição de estatal impunha uma cultura permeada por relações políticas, o que muitas vezes condicionava as ações da PrestA aos interesses do Estado, bem como, relações de camaradagem entre os funcionários, de modo que todos se sentiam parte de "uma grande família". Assim, os procedimentos administrativos e técnico-operacionais, em geral, não atendiam a prioridades definidas pelos clientes.

Em decorrência da nova estrutura organizacional, após o forte enxugamento e a eliminação de níveis hierárquicos, houve um aumento da carga de trabalho e atribuídas maiores responsabilidades aos funcionários na execução das novas rotinas organizacionais.

A PrestA foi privatizada em 21 de julho de 1997 em leilão vencido por um consórcio de quatro empresas estrangeiras, cujo controlador técnico é o maior grupo gasista da Espanha. Um mês após a privatização, a estrutura organizacional foi novamente alterada, para atender à concepção de gestão organizacional desse grupo.

O novo modelo de estrutura organizacional reduziu o número de funcionários nos anos subsequentes (até 2004) de 1.100 para 508, sendo 338 funcionários novos e 170 antigos. Portanto, a nova composição corresponde a $66,6 \%$ de funcionários novos e 38,4\% de antigos. Além disso, verificou-se que as funções desempenhadas pelos funcionários afastados da empresa não foram absorvidas pelos 508 remanescentes. De fato, foram contratadas indiretamente, via terceirização, cerca de 2.500 pessoas para suprir a carência de pessoal, as quais na sua maioria não eram ex-funcionários da empresa. 
É oportuno ressaltar que durante os dois primeiros anos e meio de privatização os cargos funcionais estratégicos foram ocupados pelos gestores espanhóis, à exceção da diretoria jurídica, que necessitava de pessoas conhecedoras da legislação brasileira. Posteriormente, estas foram substituídas por novos funcionários brasileiros contratados já na gestão recém-implantada. Somente em dezembro de 1999, uma segunda diretoria teve seu posto principal ocupado por um brasileiro: a diretoria comercial.

Em dezembro de 2003, um funcionário brasileiro foi promovido a diretor, aumentando para três, das seis existentes, o número de diretorias ocupadas por executivos brasileiros. Entretanto, recentemente, as diretorias comercial e econômico-financeira voltaram a ser ocupadas por executivos estrangeiros, permanecendo sob a responsabilidade de executivos brasileiros apenas as diretorias jurídica e de recursos humanos, além da presidência da empresa.

\section{Descrição das mudanças}

De acordo com os depoimentos dos funcionários, apesar de terem ocorrido mudanças estratégicas e estruturais, as mudanças culturais e comportamentais geraram as transformações mais significativas após a privatização da empresa.

\section{Mudanças estratégicas}

Com a privatização, ocorreu um realinhamento da estratégia de negócio da empresa. Em virtude da pouca competitividade por conta da falta de concorrência, o ambiente em que a PrestA operava era considerado estável.

Apesar de a empresa ser uma prestadora de serviço público, o foco dos seus negócios enfatizava o processamento do produto. Com a privatização, a empresa direcionou seu negócio para os interesses do mercado consumidor, tendo como diferencial a qualidade do serviço. Assim, as metas da empresa foram centradas na captação de novos clientes (residenciais, automotivos e industriais) visando sua expansão. Dessa forma, a empresa deslocou sua configuração e características de organização de bens para organização de serviço, como destacado nos seus objetivos estratégicos. Entre estes, destacam-se: ampliação da base de clientes, com expansão da rede de gasodutos; eficiência de custos; conversão para gás natural; excelência e confiabilidade de serviços.

A ênfase da empresa passou da área técnica para a área comercial, resultando no fortalecimento das relações com os clientes e fornecedores. Dessa forma, a estrutura da PrestA teve de ser alterada para atender às peculiaridades dos clientes, incluindo suas necessidades e as particularidades das regiões onde residem.

Assim, para que a empresa colocasse em prática sua estratégia de atendimento ao cliente, ela optou por descentralizar a tomada de decisões e deu mais autonomia aos chefes de departamentos. Além disso, a nova estruturação baseada na demanda e na estimativa futura do mercado resultou em novas exigências no nível da capacitação de recursos humanos. Portanto, os empregados passaram a ter mais horas de treinamento, a fim de que fossem capacitados para o relacionamento interpessoal com os clientes. Cabe ressaltar que, antes da privatização, a ênfase era dada nos treinamentos das áreas técnica e de produção, negligenciando-se a capacitação nos temas relacionados com a interação entre pessoas.

\section{Mudanças estruturais}

No caso da PrestA, observa-se que a área técnica era altamente especializada, composta por um grande número de funcionários, os quais, entretanto, desempenhavam um número limitado de tarefas. Quando a empresa foi privatizada, optou-se por reduzir a sua estrutura funcional, agregando aos cargos um maior número de tarefas e delegando mais responsabilidades e autonomia aos funcionários. Essa reestruturação resultou em muitas demissões, principalmente, na área técnica, já que nessa área se concentrava o maior número de funcionários da empresa. 
Como consequência dessa situação, foi reduzido o número de funcionários, em virtude do(a):

eliminação de níveis hierárquicos;

reagrupamento de tarefas;

enxugamento de cargos;

realinhamento de processos administrativos e produtivos;

demanda por novas especializações para o trabalho;

redefinição tanto da cadeia de comando quanto da amplitude do controle; e

redistribuição das tomadas de decisões pelos níveis hierárquicos mantidos.

A nova estrutura funcional determinou a descentralização da tomada de decisões na empresa, a partir do momento em que se passou a delegar tal poder aos níveis hierarquicamente mais baixos.

Essa nova postura tem sido insuficiente para reter na companhia talentos que acabam transferindo-se para outras empresas, atraídos por melhores salários. Segundo a pesquisa realizada, esse fato decorre da falta de um plano de carreira atraente, pois no que está em vigor, há poucos níveis intermediários entre o nível técnico e o de chefia de serviço. Assim, trata-se de um processo de ascensão funcional lento, diante das expectativas dos empregados, o que leva à desmotivação e à evasão.

Nesses anos após a privatização da PrestA, sua estrutura organizacional foi eventualmente alterada, ora por causa das demandas do mercado, ora em virtude de uma adequação à estrutura da matriz na Espanha. Como exemplo pode ser citado a criação, em 1998, da diretoria de projeto de conversão, extinta em março de 2000 e substituída por uma gerência de mesmo nome. Essa diretoria foi criada porque o contrato de concessão para explorar a prestação do serviço público na cidade do Rio de Janeiro previa a conversão do produto em todas as unidades comerciais e residenciais.

Outro aspecto a ser considerado é que a nova reorganização estrutural estimulou a terceirização. Essa estratégia, segundo Trindade e Segre (1996), visa reduzir custos operacionais e de pessoal em segmentos que, apesar de menos importantes na empresa, não podem ser desprezados, por fazerem parte do produto principal da organização.

Assim, em julho de 1997 a PrestA já havia firmado 107 contratos de prestação de serviços com empresas terceirizadas. Atualmente, a empresa possui em torno de 2.500 funcionários terceirizados. Os setores que mais utilizam essa modalidade de serviços são as diretorias técnica e comercial - com 72 contratos -, já que são as unidades organizacionais responsáveis pelas operações-fim da empresa.

Dentre as operações mantidas pelo serviço terceirizado, destacam-se:

as operações de conversão dos equipamentos de distribuição do produto;

reparos de equipamentos de gás;

serviços de emergência;

manutenção;

controle de qualidade das instalações prediais, comerciais e industriais;

pesquisa de satisfação do cliente;

leitura de medidores;

impressão e entrega de contas;

teleatendimento comercial e de emergência; 
projetos de engenharia de rede;

avaliação de imóveis; e

arquivo e distribuição de documentos.

O predomínio da terceirização das funções técnicas gerou um maior número de demissões nessa área da empresa. Com relação às terceirizações, um dos funcionários antigos relata:

Isso era tão gritante que, após a privatização, até hoje, escutamos dirigentes que dizem que agora a empresa funciona com 500 funcionários apenas. Isso não é verdade, a empresa funciona com 500 funcionários mais 2.500 terceiros. (grifo nosso)

Inicialmente, a expectativa era de que a terceirização de algumas atividades reduzisse a carga de trabalho. No entanto, em alguns casos, o resultado foi o oposto, principalmente, na área técnica, responsável pela supervisão dos serviços executados. $\mathrm{O}$ despreparo das empresas terceirizadas para executar o serviço contratado teria demandado maior tempo de supervisão em decorrência da insatisfação de clientes. Assim, as terceirizações acabaram significando, simultaneamente, demissão e aumento da carga de trabalho para os funcionários remanescentes, o que levou alguns empregados a adotarem um comportamento negativo em relação à mudança.

Entretanto, esse despreparo das empresas terceirizadas foi contornado através da construção de alianças com os fornecedores de serviços, buscando desenvolver relacionamentos de alta densidade, com padrões de laços diretos fortes e natureza colaborativa, o que gerou um alinhamento de interesses entre a empresa e seus fornecedores (BASTOS; MACEDO-SOARES, 2007).

Essa é uma realidade que demonstra o impacto que mudanças organizacionais profundas como a ocorrida na PrestA, podem causar na estrutura da organização.

\section{Mudanças culturais}

Segundo os depoimentos dos entrevistados, antes da mudança, a PrestA possuía uma cultura caracterizada pela forte ingerência política na gestão da empresa. A crença de que as coligações políticas influenciavam o destino dos funcionários e determinavam a forma de atuar da organização levava os funcionários a uma atitude descomprometida com os objetivos da empresa. Com a privatização, a nova orientação, voltada para a satisfação do cliente, redirecionou o comportamento dos funcionários, exigindo maior comprometimento com suas tarefas e com os objetivos da empresa.

Entretanto, ainda que no passado a empresa favorecesse os grupos ligados às questões políticas, os funcionários antigos afirmam que eles eram mais motivados e leais antes da empresa ser privatizada. A análise dos relatos aponta que isso decorre da valorização do profissionalismo que hoje impera na empresa, em detrimento da ênfase nos relacionamentos interpessoais, que era uma característica muito forte na cultura estatal.

Antes da privatização, a relação entre funcionários e chefes era mais fraterna e baseada na camaradagem. Após a privatização, os valores que permeiam as relações interpessoais limitam-se às questões profissionais.

De acordo com o percebido nas entrevistas, a nova gestão teve como pilar para a implementação da mudança cultural o estabelecimento e a divulgação da missão, dos valores e da visão da empresa. Estas enfatizam a excelência dos serviços, o respeito ao meio ambiente, a rentabilidade sustentável, o posicionamento de liderança como grupo energético e a ampliação de oportunidades de desenvolvimento, tanto em nível profissional quanto pessoal dos funcionários (BASTOS; MACEDO-SOARES, 2007). Em relação aos valores, estes estão voltados para o cliente, para o compromisso com os resultados; prezam o interesse pelas pessoas, a responsabilidade e a integridade. (op. cit.).

A síntese dessas diferenças culturais, construída a partir da pesquisa realizada, é apresentada no quadro 2 : 
Quadro 2 - Comparação da cultura organizacional antes e após a privatização

\begin{tabular}{ll}
\hline Cultura Organizacional antes da Privatização & Cultura Organizacional após a Privatização \\
\hline acomodação dos empregados ao status funcional & busca pelo crescimento profissional \\
\hline gestão atrelada às coligações políticas & gestão voltada para o mercado de clientes \\
\hline $\begin{array}{l}\text { ênfase na camaradagem e relacionamentos } \\
\text { interpessoais - paternalismo, corporativismo e } \\
\text { permissividade }\end{array}$ & $\begin{array}{l}\text { ênfase no profissionalismo nos relacionamentos } \\
\text { interpessoais }\end{array}$ \\
\hline $\begin{array}{l}\text { falta de padronização de comportamento dos } \\
\text { empregados diante dos clientes internos e externos }\end{array}$ & $\begin{array}{l}\text { formulação de um código de ética - padronização } \\
\text { do comportamento entre os empregados e diante dos } \\
\text { clientes }\end{array}$ \\
\hline $\begin{array}{l}\text { falta de orientação para os valores da empresa, sua } \\
\text { visão e missão }\end{array}$ & $\begin{array}{l}\text { explicitação dos valores, da visão e missão da } \\
\text { empresa }\end{array}$ \\
\hline $\begin{array}{l}\text { interesses de promoção individuais conduzem as } \\
\text { ações mercadológicas }\end{array}$ & $\begin{array}{l}\text { interesses dos clientes conduzem as ações } \\
\text { mercadológicas da empresa }\end{array}$ \\
\hline $\begin{array}{l}\text { promoções ou movimentações de cargos dependem } \\
\text { do poder das relações políticas }\end{array}$ & $\begin{array}{l}\text { promoções ou movimentações dependem das } \\
\text { habilidades e competências dos empregados }\end{array}$ \\
\hline $\begin{array}{l}\text { baixa exigência para o alcance de resultados } \\
\text { força política do sindicato de classe }\end{array}$ & $\begin{array}{l}\text { alta exigência quanto ao alcance de resultados } \\
\text { enfraquecimento político do sindicato }\end{array}$ \\
\hline
\end{tabular}

Fonte: elaborado pelos autores.

\section{Mudanças comportamentais}

Com a chegada dos novos gestores e a saída de um grande número de funcionários após a privatização, houve mudanças no quadro de pessoal da PrestA. Dentro da reestruturação organizacional advinda da privatização, observou-se que alguns funcionários antigos tornaram-se chefes de departamentos ou gerentes, conforme sua especialização técnica e experiência comprovada na área de atuação, seguindo assim o novo modelo de gestão.

Se por um lado o processo de privatização trouxe consequências vantajosas para os empregados remanescentes, por outro, colocou-os diante de uma filosofia diferente da que compartilhavam anteriormente. $\mathrm{O}$ grupo de gestores, formado por funcionários antigos, deparou-se com uma situação de adaptação a essa nova forma de gerir a empresa. Esse quadro propiciou um conflito de ideias, valores, crenças e normas, gerando resistências àquilo que é novo e, por isso, desconhecido.

A mudança no quadro de pessoal levou os funcionários antigos a terem de interagir com os novos, causando um confronto de comportamentos, valores e ideias diferentes Tal confronto não ocorreu apenas entre brasileiros novos e antigos, mas também entre brasileiros e espanhóis.

Essa interação de culturas evidenciou as diferenças de comportamento dos indivíduos. Para os espanhóis, sua maneira de compreender as mudanças diferia da dos brasileiros, conforme colocado por Freitas (1997) ao afirmar que a cultura está relacionada às diferentes formas de percepção da realidade que caracterizam comunidades distintas. $\mathrm{O}$ seguinte relato de um funcionário ilustra essa situação:

No início, tentou-se impor métodos de gestão usados na Espanha, como se eles fossem funcionar muito bem no Brasil. Hoje, todos enxergam que não poderia ter sido feito daquela forma. A área técnica é muito específica e segue as características regionais e locais, não podendo ser forçada a usar um modelo global. 
Esse relato ressalta ainda o choque de culturas em uma área específica da empresa - a área técnica. É importante identificar, dentro de uma organização, quais grupos tendem a assumir posturas mais resistentes nos momentos de mudança.

\section{Análise e interpretação dos dados}

A análise das percepções contidas nos relatos dos entrevistados será apresentada inter-relacionando as dimensões definidas no arcabouço teórico, para que melhor se possa descrever a complexidade das relações entre as variáveis.

De uma forma geral, os funcionários não acreditavam que a privatização de fato ocorreria. Contavam com a mobilização do sindicato da classe no sentido de dificultar toda e qualquer tentativa de transformar a empresa em uma corporação privada.

Aspectos culturais da organização identificados no discurso dos empregados se referem às relações interpessoais construídas antes da privatização, relações estas consideradas de camaradagem, acarretando com isso o desrespeito frequente à hierarquia formal da organização. Essas atitudes de coesão grupal reforçam a perspectiva das coligações políticas existentes antes da privatização, como meio dos funcionários antigos tentarem manter a força dos grupos políticos que se constituíram informalmente durante os anos de empresa estatal, como instrumentos eficazes na preservação dos interesses adquiridos (CALDAS; WOOD, 2007).

O tema dominante do discurso dos empregados durante as entrevistas aponta que eles acreditavam que a gestão estatal era capaz de conferir rentabilidade à empresa e que, portanto, não era necessário vendê-la. Cabe destacar que estes, porém não souberam especificar o nível dessa rentabilidade. Um funcionário da área técnica revelou: "Uma empresa, apesar de ser do Estado, ela funcionava direitinho, ela tinha renda própria, [...]. Mas ela sempre produziu alguma coisa de dinheiro." (grifo dos autores). O relato aponta que a descrença na mudança, gera resistência, mesmo que as causas para esta descrença não sejam necessariamente corroboradas pela realidade (HERNANDEZ; CALDAS, 2002).

As consequências do enxugamento do quadro de pessoal da empresa e da eliminação de níveis hierárquicos que foram mais sentidas são:

enfraquecimento do poder de alguns grupos sociais;

perda da estabilidade e de benefícios salariais;

insegurança quanto à posição na estrutura formal da empresa;

maior nível de estresse por causa do aumento da carga de trabalho; e

extinção do plano de carreira

Os relatos ouvidos durante as entrevistas revelam o desconforto de alguns grupos sociais com a privatização, principalmente, por parte daqueles que se beneficiavam do poder político. Esse sentimento levou os indivíduos ao uma atitude de resistência, reveladora de uma busca pela manutenção do que lhes era familiar, conhecido e, portanto, já experimentado (HERNANDES; CALDA, 2002; MOTTA, 2001).

O choque cultural é uma questão também presente no discurso dos empregados. Os funcionários antigos entendiam que a perda de um bem público para um grupo privado era agravada por este ser de capital estrangeiro. A crença era a de que a compra de uma empresa pública por estrangeiros remetia o país a uma condição colonial, implicando perda do patrimônio nacional.

Os conflitos entre funcionários novos e antigos ocorreram em decorrência da falta de um programa de integração entre esses dois grupos. Esse choque foi resultado, sobretudo, da pouca informação sobre o processo de mudança dirigida aos empregados de nível operacional, tanto no período de preparação da empresa para a nova gestão, quanto na fase pós-privatização. $\mathrm{O}$ acesso restrito às informações sobre os objetivos das tarefas e, 
principalmente, sobre os objetivos e o alcance da própria mudança, contribuiu para que esta fosse vista de forma negativa (MOTTA, 2001).

Por não ter havido a preocupação de integrar os funcionários com mais tempo na empresa à nova situação, estes acabaram se autoexcluindo do processo de mudança, por medo e insegurança. Esses empregados mais antigos acreditavam que com a chegada dos novos funcionários seriam demitidos, devido a um interesse na desarticulação dos grupos. Tais atitudes baseadas em emoções negativas levaram esses indivíduos a tentar preservar as amizades existentes, para se sentirem mais seguros (EVANS; DAVIS, 2005; CALDAS; WOOD, 2007; HERNANDEZ; CALDAS, 2002).

Conforme sinalizado anteriormente na seção "Multiculturalismo organizacional", a preparação para a mudança teve como objetivo reduzir a resistência aos novos padrões culturais, minimizando a instabilidade e a insegurança dos funcionários diante desse processo (SAYÃO; TANURE; DUARTE, 2006). Na empresa analisada, a preparação para a mudança não considerou a participação dos funcionários, especialmente, como já foi aqui observado, daqueles de nível operacional, os quais foram informados das transformações em curso através de memorandos. Essa preparação também é importante para viabilizar a integração entre veteranos e novatos, sejam estes brasileiros ou estrangeiros e, portanto, originários de culturas diferentes.

Quanto ao conflito entre espanhóis e brasileiros, estes consideravam que aqueles tinham uma postura "descomprometida" em relação à empresa. Esse fato gerou um sentimento de revolta nos empregados brasileiros antigos que se diziam ligados à PrestA por sentimentos de "amor" e "carinho", os quais, no seu ponto de vista, não eram compartilhados pelos estrangeiros. Nesse sentido, um funcionário de nível de chefia comentou:

[...] desde o início, eles [referindo-se aos espanhóis] estão fazendo besteira. Eles não estão fazendo um bom trabalho, em função de não conhecer o país, não conhecer as pessoas, não conhecer a cultura. Eles não conhecem e não vão conhecer nunca, porque eles ficam quatro anos e vão embora. [...] Falta comprometimento. É isso aí; e aí fica difícil. A empresa tá ganhando dinheiro? Tá crescendo? Tá crescendo. Mas se aí tivesse um envolvimento maior, a empresa estaria ganhando muito mais dinheiro, muito mais.

Segundo os funcionários antigos, havia também um sentimento de desconfiança de ambas as partes. Os espanhóis não acreditavam que os brasileiros, tanto novos quanto antigos, tivessem a qualificação técnica necessária à execução das tarefas exigidas. Pensavam também que os brasileiros poderiam boicotar os processos. Por outro lado, os brasileiros antigos acreditavam que todos seriam demitidos pelos espanhóis e que, portanto, sua situação iria piorar.

Expressões como "burro", "horror", "guerra" e "traumática" foram ouvidas nos relatos de alguns funcionários brasileiros, o que denota distanciamento em relação aos novos controladores, além de um ambiente extremamente hostil, onde a desconfiança, o ressentimento, a mágoa e o rancor são sentimentos negativos evidentes. A interpretação dos relatos dos funcionários remanescentes ante a mudança traduz o sentimento de mágoa no que diz respeito ao tratamento recebido pelos novos gestores da empresa. Esses funcionários sentiam-se humilhados e desprezados pelos novos donos, a quem acusavam de tratá-los com preconceito e de desqualificá-los. Essas explicitações de mensagens de demérito contra ações do passado demonstram juízo de valor negativo que levou a um sentimento de raiva e ressentimento entre os funcionários remanescentes, dificultando o processo de mudança (LOPEZ, 2007; WETZEL, 2000).

Portanto, entende-se que existe de forma subliminar um sentimento de desconfiança e de rejeição aos novos donos da empresa, em especial, nos escalões inferiores, o que gera aversão à gerência responsável pelas mudanças e é um dos elementos potencializadores de comportamentos resistentes às transformações organizacionais (CALDAS; WOOD, 2007; SIMON; LANE, 2004).

De acordo com os relatos, o medo da demissão e a consciência de que haveria uma maior exigência técnica foram apontados como os sentimentos de maior impacto no grupo de funcionários antigos dos níveis 
operacional e administrativo. O esforço extra para reaprender acabou despertando resistências nos indivíduos, os quais se viam, então, confrontados com situações de mudança que denunciavam suas debilidades técnicas (CALDAS; WOOD, 2007).

Essa percepção negativa que os funcionários de nível operacional tiveram do processo de mudança surgiu das condições desfavoráveis que experimentaram no exercício de suas funções: é o caso da perda de importância das habilidades/competências individuais, se comparadas à capacidade técnica dos novatos, que pode acarretar redução de salários (CALDAS; WOOD, 2007; MOTTA, 2001).

Os sentimentos de medo e insegurança que permearam o cotidiano dos funcionários, por causa das demissões em massa e do aumento da carga de trabalho, geraram estados de sofrimento (DEJOURS, 2000) que propiciaram comportamentos de aversão e resistência à nova administração.

Outro aspecto relevante verificado foi o desconforto dos funcionários em relação à forma e à rapidez do processo de enxugamento. Este não propiciou a participação das pessoas nem contou com o tempo necessário para que estas se adaptassem, fatores fundamentais para se evitar resistências (CALDAS; WOOD, 2007). Além disso, o enxugamento dos quadros demonstrou que a empresa optou por modificar a cultura e o comportamento organizacionais por meio da mudança de pessoas. Mota et al (2007) e Sayão, Tanure e Duarte (2006) consideram que essa foi uma forma equivocada de gerir o processo de mudança, enfatizando a necessidade de integração das culturas na gestão de fusões e aquisições, conforme se percebe pelos conflitos identificados na empresa pesquisada.

De modo geral, o estudo revelou que, de certa forma, todas as mudanças afetaram os funcionários das diferentes subcategorias. No entanto, há determinadas mudanças que causaram maior impacto no comportamento dos empregados de uma subcategoria específica. Ressalta-se que cada grupo de funcionários teve uma percepção diferenciada da mudança organizacional, diferença essa relacionada ao cargo ocupado pelo funcionário, ao tempo em que ele trabalha na empresa, à sua nacionalidade e às suas expectativas com relação à mudança.

O levantamento de campo, sintetizado no quadro a seguir, utilizando as subcategorias definidas no quadro 1, aponta para a existência de grupos fechados, com suas próprias normas de convivência, sinalizando a força dos grupos informais, nomeados pelos funcionários como feudos. Esses aspectos refletem a cultura de uma organização que não se modifica rapidamente, pois não segue a lógica forma de uma empresa (ROETHLISBERGER; DICKSON, 1971).

O quadro 3 ilustra, resumidamente, essas diferenças. Os números mencionados na coluna das subcategorias indicam as que sofreram maior impacto pelas mudanças correspondentes. 


\section{Quadro 3 - Comparação entre as mudanças organizacionais e seu impacto no comportamento dos} indivíduos das subcategorias

\begin{tabular}{|c|c|c|c|}
\hline Mudanças & & $\begin{array}{l}\text { Impacto no Comportamento } \\
\text { (padrão de resistência) }\end{array}$ & Subcategorias \\
\hline \multirow{10}{*}{$\begin{array}{l}\text { Estratégicas e } \\
\text { Estruturais }\end{array}$} & Empresa de serviço & $\begin{array}{l}\text { Dúvidas sobre a viabilidade técnica da } \\
\text { mudança }\end{array}$ & \multirow{10}{*}{1 e 3} \\
\hline & $\begin{array}{l}\text { Ênfase na demanda atual } \\
\text { e estimada do mercado }\end{array}$ & Esforço extra para reaprender & \\
\hline & Capacitação do pessoal & Tempo para se adaptar & \\
\hline & Gestão por competências & Medo do desconhecido & \\
\hline & $\begin{array}{l}\text { Extinção de } \\
\text { departamentos }\end{array}$ & Evidências da desatualização & \\
\hline & Reagrupamento de tarefas & Acomodação ao status funcional & \\
\hline & $\begin{array}{l}\text { Eliminação de níveis } \\
\text { hierárquicos }\end{array}$ & Exclusão do meio social & \\
\hline & $\begin{array}{l}\text { Sistema de remuneração e } \\
\text { recompensa }\end{array}$ & & \\
\hline & $\begin{array}{l}\text { Redefinição da cadeia de } \\
\text { comando }\end{array}$ & & \\
\hline & $\begin{array}{l}\text { Departamentalização } x \\
\text { processo }\end{array}$ & & \\
\hline \multirow{4}{*}{ Culturais } & $\begin{array}{l}\text { Enfraquecimento das } \\
\text { coligações políticas }\end{array}$ & Desejo de manter o status quo & \multirow{4}{*}{1 e 3} \\
\hline & $\begin{array}{l}\text { Ênfase na valorização do } \\
\text { cliente }\end{array}$ & Ressentimento - choque & \\
\hline & Código de ética & $\begin{array}{l}\text { Desejo de não perder algo considerado } \\
\text { valioso }\end{array}$ & \\
\hline & $\begin{array}{l}\text { Valores da empresa } \\
\text { explicitados }\end{array}$ & & \\
\hline \multirow{3}{*}{ Comportamentais } & $\begin{array}{l}\text { Funcionários novos } x \\
\text { antigos }\end{array}$ & $\begin{array}{l}\text { Conflitos entre funcionários novos e } \\
\text { antigos }\end{array}$ & \multirow{3}{*}{ Todas } \\
\hline & Culturais internacionais & Aversão pelo agente da mudança & \\
\hline & & Falta de confiança nos outros & \\
\hline
\end{tabular}

Fonte: elaborado pelos autores.

O quadro 4 indica as principais razões pelas quais os indivíduos se comportaram de forma diferenciada perante as mudanças implementadas.

\section{Quadro 4 - Resumo das razões da diversidade de comportamento}

\begin{tabular}{ll}
\hline Subcategoria 1 & $\begin{array}{l}\text { Informação, visão de mundo, preparo técnico, tratamento individualizado e } \\
\text { perspectiva de crescimento }\end{array}$ \\
\hline Subcategoria 2 & $\begin{array}{l}\text { Choque de relacionamento com os antigos e falta de parâmetro para uma } \\
\text { comparação }\end{array}$ \\
\hline Subcategoria 3 & $\begin{array}{l}\text { Pouca participação, pouco desenvolvimento profissional, tratamento massificado e } \\
\text { acomodação na função }\end{array}$ \\
\hline Subcategoria 4 & $\begin{array}{l}\text { Choque de relacionamento com os antigos e falta de parâmetro para uma } \\
\text { comparação }\end{array}$ \\
\hline Subcategoria 5 & Eram os gestores da empresa \\
\hline
\end{tabular}

Fonte: elaborado pelos autores 
Para os funcionários antigos, brasileiros e do nível gerencial, a mudança não teve um significado tão negativo. Os empregados do nível gerencial tiveram, desde o início da privatização, um tratamento diferenciado por fazerem parte do nível hierárquico estratégico da empresa. Assim, eles foram informados sobre o que significava o processo de mudança pelo qual a empresa passaria e tiveram acesso a informações e detalhes da modelagem que iria colocar em prática a mudança, além de terem sido recebidos e avaliados por um grupo especialista em aconselhamento e recolocação de executivos. Esse atendimento foi realizado em um hotel, fora da empresa, de forma individualizada.

Os funcionários do nível gerencial acreditavam que a mudança era necessária para a empresa se desenvolver e crescer. Eles tinham a expectativa de que a privatização lhes traria mais oportunidades de crescimento na empresa, pois acreditavam que a nova gestão valorizaria sua qualificação profissional e seu perfil pró-ativo. Além disso, esperavam que com a privatização a ingerência política na gestão da empresa seria minimizada, beneficiando quem não estava comprometido com qualquer grupo político.

Dessa forma, os funcionários compreenderam a nova situação - pois foram envolvidos no processo de mudança - e tiveram acesso às informações, o que lhes trouxe mais tranquilidade para enfrentar o novo. A informação, segundo Hernandez e Caldas (2002), é fundamental para que os empregados compreendam as razões da mudança e suas implicações, tendo assim condições de avaliar o quanto esta faz sentido para a organização.

Essa visão é reforçada por Davis e Newstrom (1996), que asseguram que a participação nos processos de mudança é fundamental para que a organização conte com o apoio dos funcionários, pois à medida que a participação aumenta, a resistência tende a decrescer.

Essa realidade observada na PrestA vem reforçar a visão de Motta (2001), que afirma que as pessoas se comprometem com as mudanças nas quais se envolvem desde o princípio. Assim, segundo o autor, favorecer a participação por meio de um fluxo constante de informação faz os funcionários sejam menos resistentes, mais realistas e cooperativos em relação à mudança.

Para os funcionários da subcategoria 3, a instabilidade profissional, o medo das demissões oriundas das profundas mudanças estruturais, a necessidade de se adaptar às novas estratégias e o pouco acesso às informações foram alguns dos motivos que levaram esse grupo de funcionários a ter uma maior rejeição.

As subcategorias 2 e 4, como apontado anteriormente, não tinham expectativas com relação à mudança. Apenas verificaram resistência entre funcionários novos e antigos.

Os executivos expatriados, pertencentes à subcategoria 5, afirmam que a expectativa dos funcionários da empresa quanto à mudança variou conforme os grupos. Havia grupos mais receptivos à mudança, que se adaptaram ao novo perfil da empresa, enquanto outros não aceitavam a privatização, pois ela representava a perda de privilégios que a nova gestão não estava disposta a manter. Quanto a este grupo, Motta (2001) entende que a tentativa de manutenção do status quo é natural, pois à medida que as pessoas permanecem numa mesma instituição ou empresa, tendem a se apegar a conquistas. Portanto, qualquer iniciativa para alterar essa situação acaba enfrentando a resistência dos beneficiados por tais conquistas.

Os expatriados (subcategoria 5), por terem sido os gestores da mudança, obviamente, não apresentaram comportamento conflitante com os objetivos propostos pela empresa. Porém, curiosamente, os expatriados que fixaram residência no Brasil (obtiveram visto permanente) e estão no país há mais de cinco anos, os quais constituíram família com brasileiras, admitiram que houve problemas de relacionamento com os brasileiros. Eles atribuem aos espanhóis a maior parcela de culpa pela incapacidade de lidar com a situação. 
Quadro 5 - Comparativo entre as expectativas com relação às mudanças e as subcategorias

\begin{tabular}{|c|c|c|}
\hline \multirow{2}{*}{ Subcategorias } & \multicolumn{2}{|c|}{ Expectativas } \\
\hline & Positivas & Negativas \\
\hline \multirow{5}{*}{1} & Evolução técnica e administrativa & Perda do poder político \\
\hline & Melhor imagem externa da empresa & Perda do prestígio pessoal \\
\hline & Crescimento profissional & $\begin{array}{l}\text { Insegurança quanto à posição na estrutura } \\
\text { formal da empresa }\end{array}$ \\
\hline & Modernização dos processos da empresa & Desconfiança em relação à gestão estrangeira \\
\hline & Remuneração variável & \\
\hline 2 & Não havia expectativas - empregados novos & \\
\hline \multirow{7}{*}{3} & $\begin{array}{l}\text { Oportunidade de crescimento sem interferência } \\
\text { política }\end{array}$ & Medo da demissão \\
\hline & Mais treinamento & Perda de benefícios \\
\hline & Modernização da infraestrutura da empresa & Perda dos companheiros \\
\hline & & Evidência de inabilidade técnica \\
\hline & & Ter que mudar a maneira de realizar as tarefas \\
\hline & & Desconfiança em relação à gestão estrangeira \\
\hline & & Aumento da carga de trabalho \\
\hline 4 & Não havia expectativas - empregados novos & \\
\hline \multirow[t]{2}{*}{5} & $\begin{array}{l}\text { Contribuir para o progresso econômico da } \\
\text { empresa }\end{array}$ & \multirow{2}{*}{$\begin{array}{l}\text { Resistência dos empregados à cultura } \\
\text { estrangeira }\end{array}$} \\
\hline & Melhorar processos & \\
\hline
\end{tabular}

Fonte: elaborado pelos autores.

O quadro 5 mostra que empregados de subcategorias específicas também têm expectativas diferenciadas quanto às mudanças. Assim, pode-se relacionar o comportamento dos grupos de indivíduos diante das transformações organizacionais com o cruzamento:

das percepções individuais;

do cargo ocupado pelo funcionário;

do tempo em que trabalha na empresa;

da nacionalidade; e

das expectativas sobre a mudança.

Assim, a diversidade de expectativas e percepções reforça a teoria de Bowditch e Buono (1997) segundo os quais a percepção individual sobre a realidade, e a forma como esta é interpretada, influencia o comportamento do indivíduo ante a mudança organizacional.

\section{Conclusão}

A partir de teorias que corroboram os resultados da pesquisa, podem ser destacados alguns aspectos referentes à relação entre as mudanças organizacionais nos processos de privatização e o impacto destas na cultura e no comportamento dos indivíduos. Deve-se destacar que, no caso da empresa PrestA, em particular, esses impactos podem ter sido acentuados por tratar-se de um controlador de cultura estrangeira. Considerando-se esses aspectos, podem ser apontadas as seguintes características que permitem entender o comportamento dos empregados após as mudanças: 
as ações de reestruturação de curto prazo que resultam em grande número de funcionários demitidos são responsáveis pela maior parte dos sentimentos negativos dos empregados remanescentes acerca da mudança;

a contratação de novos empregados representa uma ameaça para os remanescentes, pois evidencia a desvantagem dos funcionários antigos em relação aos novos, do ponto de vista da formação e do conhecimento das novas tecnologias;

o esforço extra dos funcionários antigos para se adaptarem à maior carga de trabalho decorrente do enxugamento de pessoal e a intensa cobrança tanto por resultados na execução de atividades paralelas quanto pelo cumprimento de metas e de prazos acabam causando um maior nível de estresse, conforme destacado por Bordia (2004);

a falta de informação sobre o processo de mudança, assim como o acesso desigual a essa informação, entre os diferentes níveis hierárquicos na empresa, gera resistências. Essa comunicação precária tende a alijar indivíduos desse processo de transformação, contribuindo para que haja um ambiente de medo, insegurança, revolta e ressentimento;

os conflitos nos relacionamentos interpessoais marcados por diferenças culturais, bem como entre empregados recém-admitidos e aqueles remanescentes do processo de mudança podem igualmente desencadear conflitos organizacionais.

Conforme já sinalizado na seção "Privatização e mudanças organizacionais", os processos de privatização trazem mudanças traumáticas, particularmente, no que se refere à diferença existente entre a gestão pública e a privada. Esse choque se acentua quando os novos gestores são de outra nacionalidade. $\mathrm{O}$ estudo de caso aqui apresentado corrobora esse aspecto, ao mostrar que a cultura nacional espanhola possui características mais individualistas, uma vez que considera que as pessoas são mais produtivas quando trabalham sozinhas. Esse fato propiciou conflitos no relacionamento entre espanhóis e brasileiros, já que estes apresentam uma cultura coletivista.

Cabe observar que a empresa estudada era fortemente influenciada por uma cultura que privilegiava as coligações políticas de poder. Tal perfil pode gerar frustrações e resistência dos funcionários às mudanças, sentimentos presentes no discurso dos empregados remanescentes da PrestA. Desse modo, quando ocorre uma drástica mudança na empresa, seus valores, suas normas e crenças são desestabilizados e questionados, abrindo espaço para a formação de uma nova cultura organizacional. Entretanto, com a nova cultura, o poder anteriormente constituído por meio das coligações políticas também se fragiliza e enfraquece, dando lugar a novas formas de poder através de relações políticas renovadas. Nesse sentido, nas empresas em que a estabilidade no emprego é um elemento de destaque da cultura organizacional, observa-se uma acomodação dos funcionários à situação e, consequentemente, uma reação negativa quando essa situação é ameaçada.

Observam-se atitudes de resistência com a chegada de novos indivíduos em ambientes onde as relações interpessoais estão consolidadas, os grupos informais estão construídos e a forma de se trabalhar está definida. Diferentemente do que se poderia supor, esses comportamentos resistentes não partem exclusivamente de funcionários antigos. Funcionários novos, brasileiros ou estrangeiros, também buscam evidenciar as fragilidades de indivíduos remanescentes como forma de consolidar a nova cultura, desmerecendo a antiga. Assim, percebe-se que não são apenas empregados antigos que sofrem o impacto das mudanças. Na verdade, a busca constante pelo equilíbrio entre culturas diferentes contribui para a formação da cultura organizacional que se firmará como resultado final. 


\section{Referências}

BASTOS, S. A. P.; MACEDO-SOARES, T. D. L. v. A. Impacto estratégico dos fatores macroambientais no desempenho de concessões de serviços públicos: a CEG e a CEG Rio na ótica relacional. Revista de Administração Pública, v.41, n.4, p.733-767, jul./ago. 2007.

BAUMOL, W. J; BLINDER, A.; WOLFF, E. Downsizing in America: reality, causes and consequences. Nova York: Russel Sage Foundation, 2003.

BERARDI, F. A fábrica da infelicidade. Rio de Janeiro: DP \& A, 2005.

BORDIA, P. Uncertainty during organizational change: types, consequences and management strategies. Journal of Business and Psychology, v.18, n.4, 2004.

BOWDITCH, James L; BUONO, Anthony F. Elementos de comportamento organizacional. São Paulo: Pioneira, 1997.

BRADLEY, J. Methodological issues and practices in qualitative research. Library Quarterly, v.63, n.4, Oct. 1993.

CALDAS, M. P.; WOOD, T. Comportamento organizacional: uma perspectiva brasileira. São Paulo: Atlas, 2007.

CHANLAT, J. F. (Org.). O indivíduo na organização: dimensões esquecidas. São Paulo: Atlas, v.1, 1994.

. (Org.). O indivíduo na organização: dimensões esquecidas. São Paulo: Atlas, v.2, 1996a.

(Org.). O indivíduo na organização: dimensões esquecidas. São Paulo: Atlas, v.3, 1996b.

DAFT, R. L. Teoria e projeto das organizações. Rio de Janeiro: LTC, 1999.

. Organizações: teoria e projetos. São Paulo: Pioneira Thomson Learning, 2001.

DAVIS, K.; NEWSTROM, J. W. Comportamento humano no trabalho: uma abordagem organizacional. São Paulo: Pioneira, 1996.

DEJOURS, C. A loucura do trabalho: estudo da psicopatologia do trabalho. São Paulo: Cortez, 1987.

. A Banalização da injustiça social. São Paulo: Editora FGV, 2000.

EVANS, W. R.; DAVIS D. W. High-performance work systems and organizational performance: the mediating role of internal social structure. Journal of Management, n.31, 2005.

FREITAS, A. B. Traços brasileiros para uma análise organizacional. In: MOTTA, Fernando C. Prestes; CALDAS, Miguel. P. (Org.). Cultura organizacional e cultura brasileira. São Paulo: Atlas, 1997.

HENNART, J. F.; ZENG, M. Cross-cultural differences and joint venture longevity. Journal of International Business Studies, v.33, n.4, 2002

HERNANDEZ, J. M. C.; CALDAS, M. P. Resistência à mudança. In: WOOD JR., Thomaz (Coord.). Gestão empresarial: o fator humano. São Paulo: Atlas, 2002.

HOFSTEDE, G. et al. Measuring organizational cultures: a qualitative and quantitative study across twenty cases. Administrative Science Quarterly, v.35, June 1990.

LOPEZ, S. H. Culture change management in long-term care: a shop-floor view. Politics \& Society. 2007. Disponível em: <http://www.sagepublications.com>. Acesso em: 12 fev. 2008.

LYLES, M. A.; SALK, J. E. Knowledge acquisitions from forging parents in international joint ventures: an empirical examination in the Hungarian context. Journal of International Business Studies, v.27, n.5, 1996.

MORGAN, G. Imagens da organização. São Paulo: Atlas, 1996.

MOTA, M. O. et al. Uma reflexão crítica sobre o sofrimento dos empregados durante a implementação de mudanças organizacionais. In: ENCONTRO DA ANPAD, 31., 2007, Rio de Janeiro. Anais... [S.I: s.n.], 2007.

MOTTA, P. R. Transformação organizacional: a teoria e a prática de inovar. São Paulo: Qualitymark, 2001.

POTHUKUCHI, V. et al. National and organizational culture differences and international joint venture performance. Journal of International Business Studies, v.33, n.2, 2002.

ROETHLISBERGER, F.; DICKSON, W. A organização e o trabalhador. São Paulo: Atlas, 1971. 
ROSSETTI, J. P. Fusões e aquisições no Brasil: as razões e os impactos. In: BARROS, B. T. (Org.). Fusões, aquisições e parcerias. São Paulo: Atlas, 2001.

SAYÃO, A. C.; TANURE, B.; DUARTE, R. G. Mudanças na cultura pós-aquisição: o caso da empresa Alfa. In. ENCONTRO DA ANPAD, 30., 2006, Salvador. Anais... [S.I.: s.n.], 2006.

SCHEIN, E. H. Organizational culture and leadership. San Francisco: Jossey-Bass Publisher, 1992.

SIMON D. G.; LANE P. J. A model of cultural differences and international alliance performance. Journal of International Business Studies, v.35, n.4, 2004.

TRINDADE, J. T.; SEGRE, L. M. Mudanças organizacionais em lojas de departamentos: adoção de tecnologias de informação e terceirização. Boletim Técnico do Senac, Rio de Janeiro, v. 22, n.2, maio/ago. 1996.

WALSH, K. Interpreting the impact of culture on structure - the role of change processes. The Journal of Applied Behavioral Science, v.40, n.3, Sept. 2004.

WETZEL, U. Histórias de recomeço: privatização e downsizing. Rio de Janeiro: Mauad, 2000.

WOOD, JR. Mudança organizacional: introdução ao tema. In: WOOD JR. T. (Coord.). Mudança organizacional: aprofundando temas atuais em administração de empresas. São Paulo: Atlas, 1995.

YIN, R. K. Estudo de caso: planejamento e métodos. São Paulo: Bookman, 2002.

\footnotetext{
${ }_{2}^{1}$ O nível gerencial se refere aos diretores, gerentes e chefes de serviço.

${ }^{2}$ Ações estratégicas da empresa, como o lançamento de um novo produto ou o início de uma nova campanha de divulgação de serviços.
} 